\title{
Characteristics of Lipoprotein Peak x Eluted from a Column with the Eluent of High-magnesium Ion Concentration in Lipoprotein Analysis Using the Cation-exchange Chromatography
}

\author{
${ }^{1}$ Yuji Hirowatari,${ }^{2}$ Hiroshi Yoshida, ${ }^{1}$ Yutaka Ogura, ${ }^{2}$ Hidekastu Yanai, ${ }^{3}$ Hideo Kurosawa and ${ }^{2}$ Norio Tada \\ ${ }^{1}$ Scientific Instruments Div., TOSOH Corp., 2743-1 Hayakawa Ayase-shi, Kanagawa 252-1123, Japan \\ ${ }^{2}$ Division of General Medicine, Department of Internal Medicine, Kashiwa Hospital, Jikei University \\ School of Medicine, 163-1 Kashiwashita Kashiwa-shi, Chiba 277-8567, Japan \\ ${ }^{3}$ Department of Clinical Laboratory, University Hospital, Jikei University School of Medicine, 3-25-8 \\ Nishi-shinbashi Minato-ku, Tokyo 105-8461, Japan
}

\begin{abstract}
The new lipoprotein analysis method using a cation-exchange chromatography, which contains a sulfopropyl-ligand column and two magnesium ion-containing eluents was previously reported. This method can separate serum lipoproteins on the column gel with a magnesium ion concentration gradient and high-density lipoprotein (HDL), low-density lipoprotein (LDL), very-low-density lipoprotein (VLDL) and an unspecified lipoprotein peak are eluted in order from the column. We have now characterized the unspecified lipoproteins, designated peak $\mathrm{x}$, which is last eluted from the column with the eluent of high-magnesium ion concentration. The peak $\mathrm{x}$ was small size chylomicron fraction with a part of VLDL. Furthermore, the cholesterol values in the peak $\mathrm{x}$ were significantly correlated with remnant-like particle (RLP)-cholesterol values. The peak x separated from a hyperlipidemic patient included apolipoprotein B-100, B-48, E, A-1 and Cs (C-I, C-II, C-III) and its composition of free cholesterol, cholesteryl esters, triglyceride (TG) and phospholipids in total lipids were $6,15,66$ and $13 \%$, respectively. These results suggest that a major part of the lipoprotein peak X may be composed of remnants of chylomicron and VLDL, but it remains to be elucidated.
\end{abstract}

Key words: Lipoprotein, chromatography, peak X, remnant, chylomicron, VLDL

\section{INTRODUCTION}

Hyperlipidemia is a risk factor for atherosclerotic events, i.e., coronary heart disease, cerebral infarction and pulmonary infarction ${ }^{[1-5]}$. These patients often exhibit abnormal metabolism of lipids, including cholesterol, triglyceride (TG), phospholipids and cholesteryl esters ${ }^{[6]}$, so that measurement of lipoprotein classes, high density lipoprotein (HDL), low density lipoprotein (LDL), intermediate-density lipoprotein (IDL), very low density lipoprotein (VLDL), chylomicrons is clinically important. Various methods for analysis of lipoproteins by ultracentrifugation ${ }^{[7-9]}$,electrophoresis ${ }^{[10,11]}, \quad$ gelpermeation chromatography ${ }^{[12-14]}$, anion- exchange chromatography ${ }^{[15,16]}$ and cation-exchange chromatography ${ }^{[17]}$ were reported.

In sera of Coronary Heart Disease (CHD) patients, remnants of chylomicrons and VLDL, including IDL, are increased ${ }^{[18-21]}$. These $\mathrm{TG}$ rich lipoproteins are cataborized products from chylomicrons and VLDL under the interaction with lipoprotein lipase ${ }^{[19,20]}$. These lipoprotein remnants are supposed to promote atherosclerosis ${ }^{[18,19,21]}$. Presently, an immunoseparation method is applied to measure cholesterol values of remnant like particles (RLP) of patients with hyperlipidemia $^{[18]}$.

Recently, we have developed a new cation-exchange chromatography method using a sulfopropyl-ligand column with eluents containing magnesium ions ${ }^{[17]}$. In the HPLC method, HDL, LDL, VLDL and an unspecified lipoprotein peak (peak $\mathrm{x}$ ) are separated and eluted from the column. The cholesterol values in these separated lipoproteins are determined by a postcolumn reaction using a reagent containing cholesterol esterase and cholesterol oxidase. The last eluted lipoproteins (peak $\mathrm{x}$ ) from the column with the eluent of high-magnesium ion concentration was appeared at high level in sera of hyperlipidemic patients $^{[17]}$. However, the characteristics of the lipoprotein peak $\mathrm{x}$ were not well known and thereby some details about the peak $\mathrm{x}$ were investigated in the present study.

\section{MATERIALS AND METHODS}

The enzymatic cholesterol reagent for HPLC was a commercially available Cholesterol-E test (Wako Pure Chemical Industries, Osaka, Japan). Total cholesterol, free cholesterol, total phospholipids, total triglyceride

Corresponding Authors: Yuji Hirowatari, Scientific Instruments Division, TOSOH Corp., 2743-1 Hayakawa Ayase-shi, Kanagawa 252-1123, Japan, FAX: +81-467-76-9932, Hiroshi Yoshida, MD, PhD, Division of General Medicine, Department of Internal Medicine, Kashiwa Hospital, Jikei University School of Medicine, 163-1 Kashiwashita, Kashiwa-shi, Chiba 277-8567, Japan, Fax: +81-4-7164-1126 
and RLP-cholesterol (RLP-C) in samples were determined enzymatically using commercially available kits, Tcho-L, Free cholesterol-E test, Phospholipid-E test, TG-LH (Wako Pure Chemical Industries, Japan) and Jimro-II (Japanese Immunoresearch Laboratories Co., Japan), respectively. The values of cholesteryl esters were estimated as difference between total cholesterol and free cholesterol. Values of HDL-C, LDL-C, VLDL-C and cholesterol of peak $\mathrm{x}$ were obtained by using a cation-exchange chromatography method.

\section{Chromatography: The cation-exchange} chromatographic method reported previously was performed with a part of modification ${ }^{[17]}$. The column was TSK-gel SP-NPR (4.6 mm I.D. x $20 \mathrm{~mm}$ in size, Tosoh corp., Japan), which contained $2.5 \mu \mathrm{m}$ nonporous polymer-based gel with sulfopropyl ligands. Eluent A (50 mmol L $\mathrm{L}^{-1}$ Tris- $\mathrm{HCl}+10 \mathrm{mmol} \mathrm{L}^{-1}$ magnesium acetate $\mathrm{pH} 7.5)$ and eluent $\mathrm{B}\left(50 \mathrm{mmol} \mathrm{L}{ }^{-1}\right.$ Tris- $\mathrm{HCl}+$ $10 \mathrm{mmol} \mathrm{L}^{-1}$ magnesium acetate $+500 \mathrm{mmol} \mathrm{L}^{-1}$ magnesium nitrate, $\mathrm{pH}$ 7.5) were used to separate the lipoproteins. The gradient patterns for separation of the lipoprotein classes were followed orderly with 0-50\% linear gradient of eluent B for 0-9.5 min, $50 \%$ eluent B for 9.5-12 min, $100 \%$ eluent $B$ for 12-15 min and $0 \%$ eluent B for 15-25 min. Figure 1 shows a representative chromatogram of healthy serum with the gradient pattern indicated by a hatched line. The flow rate of the eluents was $0.35 \mathrm{~mL} \mathrm{~min}^{-1}$. The eluate from the column was mixed with an enzymatic cholesterol reagent (flow rate, $0.18 \mathrm{~mL} \mathrm{~min}{ }^{-1}$ ) and reacted $37^{\circ} \mathrm{C}$ for $5 \mathrm{~min}$ in a Teflon coil $(0.4 \mathrm{~mm}$ I.D. x $21 \mathrm{~m})$. The reacted eluate was monitored at $600 \mathrm{~nm}$. The injected volume of serum sample was $3.5 \mu \mathrm{L}$.

The gel-permeation chromatography method reported previously was performed with a part of modification ${ }^{[12]}$. Two columns (TSK-gel LipopropakXL, $7.8 \mathrm{~mm}$ I.D. x $300 \mathrm{~mm}$ in size, Tosoh corp., Japan) were connected and an eluent $\left(50 \mathrm{mmol} \mathrm{L}{ }^{-1}\right.$ Tris- $\mathrm{HCl}+350 \mathrm{mmol} \mathrm{L}^{-1}$ sodium perchlorate $\mathrm{pH} 7.5$ ) was poured at rate $0.7 \mathrm{~mL} \mathrm{~min}^{-1}$. The eluate of the columns was mixed with an enzymatic cholesterol reagent (flow rate, $0.18 \mathrm{~mL}$ $\left.\min ^{-1}\right)$ and reacted $37^{\circ} \mathrm{C}$ for $5 \mathrm{~min}$ in a Teflon coil $(0.4$ $\mathrm{mm}$ I.D. x $21 \mathrm{~m}$ ). The reacted eluate was monitored at $600 \mathrm{~nm}$.

Samples: The sera from hyperlipidemic patients (patient 1, TC $=7.99 \mathrm{mmol} \mathrm{L}^{-1}, \mathrm{TG}=2.83 \mathrm{mmol} \mathrm{L}^{-1}$, RLP-C $=0.35 \mathrm{mmol} \mathrm{L}^{-1}$, HDL-C $=1.06 \mathrm{mmol} \mathrm{L}^{-1}$, LDL-C $=4.18 \mathrm{mmol} \mathrm{L}^{-1}, \mathrm{VLDL}-\mathrm{C}=2.45 \mathrm{mmol} \mathrm{L}^{-1}$ and cholesterol value of peak $\mathrm{x}=0.31 \mathrm{mmol} \mathrm{L}^{-1}$;

patient 2, TC $=6.49 \mathrm{mmol} \mathrm{L}^{-1}, \mathrm{TG}=4.93 \mathrm{mmol} \mathrm{L}^{-1}$, RLP-C $=0.62 \mathrm{mmol} \mathrm{L}{ }^{-1}$, HDL-C $=0.79 \mathrm{mmol} \mathrm{L}^{-1}$, LDL-C $=0.91 \mathrm{mmol} \mathrm{L}^{-1}, \quad$ VLDL-C $=3.89 \mathrm{mmol} \mathrm{L}^{-1}$

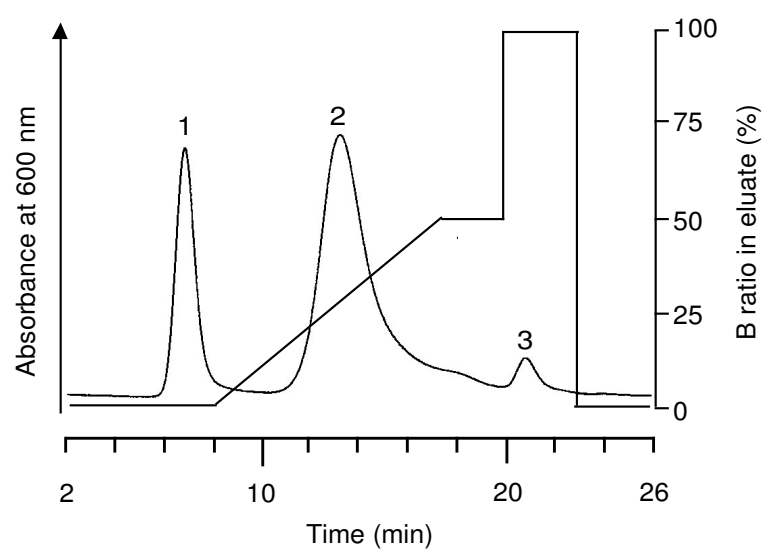

Fig. 1: Chromatogram of healthy serum and gradient pattern. The pattern of lipoprotein profile and gradient pattern are indicated by a solid line and dotted line, respectively. Serum lipid level of sample for chromatogram was as follows: $\mathrm{TC}=5.02 \mathrm{mmol} \mathrm{L}^{-1}$, $\mathrm{TG}=0.95 \mathrm{mmol} \mathrm{L}{ }^{-1}$, RLP-C $=0.10 \mathrm{mmol} \mathrm{L}^{-1}$. Retention times of peaks 1 (HDL), 2 (LDL) and 3 (peak x) were 6.81, 12.23 and $20.80 \mathrm{~min}$, respectively. The LDL and VLDL peaks in the serum were not separated. The cholesterol values of HDL, LDL, VLDL and peak $x$ were $1.27 \mathrm{mmol} \mathrm{L}^{-1}, 3.50 \mathrm{mmol}$ $\mathrm{L}^{-1}, 0.00 \mathrm{mmol} \mathrm{L}^{-1}$ and $0.23 \mathrm{mmol} \mathrm{L}{ }^{-1}$, respectively.

and cholesterol value of peak $\mathrm{x}=0.90 \mathrm{mmol} \mathrm{L}^{-1}$ ) were used for separation of HDL, LDL, IDL, VLDL and two chylomicron fractions (flotation constants (Sf) total fraction, $>400$ and large size fraction, $>800$ in a sodium chloride solution of density $\left.=1.006 \mathrm{~g} \mathrm{~mL}^{-1}\right)$ by ultracentrifugation. Sixteen healthy sera $(\mathrm{TC}$, mean $=$ $5.16 \mathrm{mmol} \mathrm{L}^{-1}, \mathrm{SD}=0.36 \mathrm{mmol} \mathrm{L}^{-1} ; \mathrm{TG}$, mean $=0.87$ $\mathrm{mmol} \mathrm{L}{ }^{-1}, \mathrm{SD}=0.43 \mathrm{mmol} \mathrm{L}^{-1}$ ) and 34 hyperlipidemic $\left(\mathrm{TC}\right.$, mean $=5.95 \mathrm{mmol} \mathrm{L}^{-1}, \mathrm{SD}=0.99 \mathrm{mmol} \mathrm{L}^{-1}$; TG, mean $=4.44 \mathrm{mmol} \mathrm{L}^{-1}, \mathrm{SD}=1.96 \mathrm{mmol} \mathrm{L}^{-1}$ ) sera were used to examine comparisons between RLP-C values and the lipoprotein cholesterol data obtained by the cation-exchange chromatography method.

Ultracentrifugation ultracentrifugation performed by previously $^{[7-9]}$. The chylomicron fraction, latation rates of total chylonicron fraction, large size chylomicron fraction and VLDL were set at $>400,>800$ and $<400$, respectively, in a solution of $1.745 \mathrm{~mol} \mathrm{~L}^{-1}$ sodium chloride $\left(\mathrm{d}=1.006 \mathrm{~g} \mathrm{~mL}^{-1}\right)$. Densities of IDL, LDL and HDL were set as follows: $1.006<\mathrm{d}<1.019 \mathrm{~g}$ $\mathrm{mL}^{-1}, \quad 1.019<\mathrm{d}<1.063 \mathrm{~g} \mathrm{~mL}^{-1}$ and $1.063<\mathrm{d} \mathrm{g} \mathrm{mL}^{-1}$, respectively. An RPS40T swing rotor and an RP55T 
angle rotor with $\mathrm{SCP} 70 \mathrm{H} 2$ ultracentrifuge (Hitachi Koki Co., Japan) were used to acquire the total and large size chylomicron fractions and the other lipoprotein fractions, respectively.

Correlation test: The correlations between cholesterol values of each lipoprotein measured by the HPLC method and those estimated by an ultracentrifugation method or RLP-C values were evaluated by Pearson product-moment correlation coefficients.

Fractionation of peak $\mathbf{x}$ : A hyperlipidemic serum (TC $=6.98 \mathrm{mmol} \mathrm{L}^{-1}, \mathrm{TG}=7.76 \mathrm{mmol} \mathrm{L}{ }^{-1}, \mathrm{HDL}-\mathrm{C}=0.82$ mmol L ${ }^{-1}$, LDL-C $=2.50 \mathrm{mmol} \mathrm{L}^{-1}$, VLDL-C $=3.00$ mmol L ${ }^{-1}$, cholesterol value of peak $\mathrm{x}=0.66 \mathrm{mmol} \mathrm{L}^{-1}$ ) was used for fractionation of the peak $\mathrm{x}$. The $10 \mu \mathrm{L}$ volume of the serum was separated by the cation-exchange chromatography method and the peak x (20-24 min) was fractionated. The fractionated sample was concentrated to the volume of 100 times using the centrifugal filter device of molecular weight cut-off 30,000 (Centricon YM-30, Millipore, USA).

Electrophoresis: The concentrated peak x sample was analyzed by sodium dodecyl sulfate polyacrylamide gel electrophoresis (SDS-PAGE) with 2-mercaptoethanol. The protein staining was performed with Coomassie Brilliant Blue. A goat polyclonal antibody against human apolipoprotein B (Rockland, USA), an alkaline phosphatase conjugated rabbit polyclonal antibody against anti-goat antibody (Zymed, USA) and NBT/BCIP substrate (1-step NBT/BCIP, Pierce, USA) were used for Western blotting experiments.

\section{RESULTS}

Chromatograms of the separated fractions by ultracentrifugation: The 6 lipoprotein fractions separated from 2 hyperlipidemic sera by ultracentrifugation method were analyzed to characterize the peak $\mathrm{x}$, indicated as peak 4 in Fig. $2 \mathrm{~A} \mathrm{~g}$ and 2B g. HDL, LDL, IDL, VLDL and total chylomicrons derived from two patients' sera were eluted in order (Fig. 2A a-e and 2B a-e). The peak $\mathrm{x}$ lipoproteins were appeared in VLDL and chylomicrons (Fig. 2A d, e and 2B d, e) of which retention times (min) were 20.86, 20.98, 21.07 and 21.25, respectively. The cholesterol values of total chylomicrons sample measured by the HPLC method accounted for about 70 $\%$ of those measured by just using an enzymatic cholesterol reagent without the HPLC (Fig. 2A e and $2 \mathrm{~B}$ e) (data not shown). Additionally, the large size chylomicrons $(>800)$ in patient 1 serum did not contain peak $x$ (Fig. 2A $f$ ) and peak $x$ of the large size chylomicrons in patient 2 serum was tiny as compared to that of total chylomicrons (Fig. $2 \mathrm{~B}$ e and f). Consequently, a large fraction of chylomicrons was likely to be hardly eluted from the column. These results suggest that the density of lipoproteins in peak $\mathrm{x}$ is $<1.006 \mathrm{~g} \mathrm{~mL}^{-1}$ and the peak $\mathrm{x}$ is the mixture of a part of VLDL and small size chylomicrons.
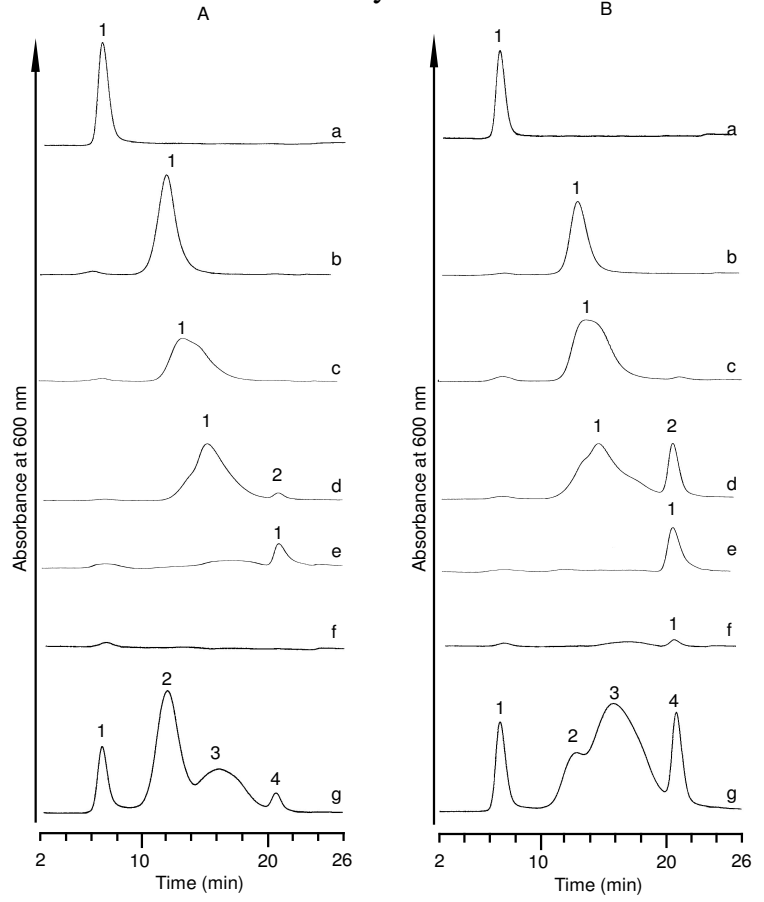

Fig. 2: Chromatograms of lipoprotein fractions separated from hyperlipidemic sera by ultracentrifugation.

Samples for chromatograms a, b, c, d, e and $\mathrm{f}$ are HDL, LDL, IDL, VLDL, total chylomicron (Sf, >400) and large size chylomicron (Sf, >800) separated from serum of hyperlipidemic patients by the ultracentrifugation method, respectively. Chromatogram $\mathrm{g}$ is a chromatographic pattern of the whole serum. Peaks 1, 2, 3 and 4 in chromatogram $g$ indicate HDL, LDL, VLDL and peak x, respectively. A: The serum of hyperlipidemic patient 1 was applied. Retention times of peak 1 in a, b and c, peaks 1 and 2 in d, peak 1 in e and peaks 1, 2, 3 and 4 in $\mathrm{g}$ were $6.68,12.03,13.07,15.27,20.86,20.98,6.65$, 11.93, 16.15, $20.62 \mathrm{~min}$, respectively. B: The serum of hyperlipidemic patient 2 was applied. Retention times of peak 1 in a, b and c, peaks 1 and 2 in d, peak 1 in e, peak 1 in $\mathrm{f}$ and peaks $1,2,3$ and 4 in $\mathrm{g}$ were $6.80,13.07,13.76,14.96,21.07,21.25,20.91,6.82$, $12.89,15.88$ and $20.87 \mathrm{~min}$, respectively.

Comparison of cholesterol values in lipoproteins measured by the HPLC method with RLP-C values: Samples used for the comparisons were sera from 16 healthy subjects and 34 hyperlipidemic patients. VLDL-C values measured by the HPLC method were modestly correlated with RLP-C $(\mathrm{r}=0.551, \mathrm{p}<0.001)$, but HDL-C and LDL-C were not correlated with RLP-C (Fig. 4A-C). Cholesterol values of the peak $x$ were significantly correlated with RLP-C values ( $r=$ 0.813, p<0.001) (Fig. 3D). 

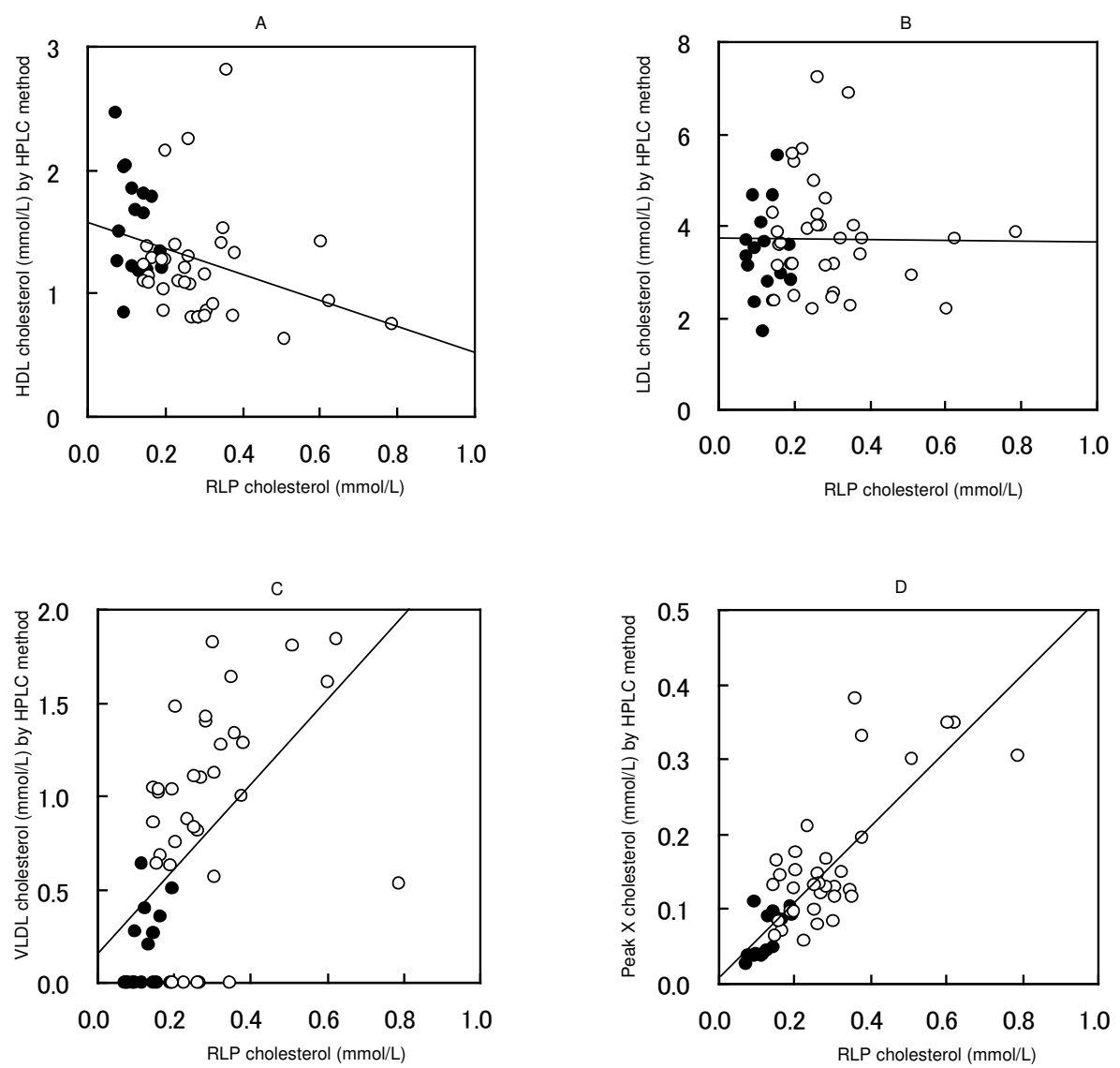

Fig. 3: Correlations of RLP-C values to HDL-C, LDL-C, VLDL-C and peak x cholesterol values measured by the HPLC method. Aliquots of $3.5 \mu \mathrm{L}$ of 50 sera were analyzed by the HPLC method and the cholesterol concentrations of each lipoprotein were determined. RLP-C values of these sera were determined by using a commercial kit (Jimro-II, Japanese Immunoresearch Laboratories Co., Japan). The data derived from 16 healthy sera and 34 hyperlipidemic sera are expressed by closed circles and open circles, respectively. Figures A, B, C and D show the correlations of RLP-C values to HDL-C, LDL-C, VLDL-C and peak $\mathrm{x}$ cholesterol values, respectively. Linear regression equations and correlation coefficients were as follows: A, $\mathrm{y}=-1.034 \mathrm{x}+1.569 \mathrm{r}=0.104 \mathrm{p}=0.0223 ; \mathrm{B}, \mathrm{y}=-0.018 \mathrm{x}+3.689 \mathrm{r}=0.0077 \mathrm{p}=0.994 ; \mathrm{C}$, $\mathrm{y}=2.231 \mathrm{x}+0.165 \mathrm{r}=0.551 \mathrm{p}<0.0001 ; \mathrm{D}, \mathrm{y}=0.494 \mathrm{x}+0.011 \mathrm{r}=0.813 \mathrm{p}<0.0001$.

Analysis of the fractionated peak $x$ by the gel-permeation chromatography and SDS-PAGE: Figure 4 shows the pattern of gel-permeation chromatography of the fractionated peak $x$. Retention time at the peak 1 and peak 2 (16.85 and 20.93 min) are exclusion limit position of this used column, which is molecular weight about $3.0 \times 10^{8}$ and the eluted position of protein of molecular weight $1.7 \times 10^{7}$, respectively (Fig. 4). This result indicates that the peak $x$ size is no smaller than VLDL size, because VLDL size is $1.0-4.9 \times 10^{7[9]}$.

Figure 5 shows the electrophoretic data of the peak $\mathrm{x}$. The molecular weight of arrowhead 1 of lane peak $\mathrm{x}$ in Fig. 6A and 6B were similar that of arrowhead 1 of lane LDL. This band was detected by Western blotting with anti-apolipoprotein B (Fig. 5C). Therefore, this protein of arrowhead 1 of lane peak $\mathrm{x}$ is apolipoprotein B-100 (Fig. 5). The molecular weight of the arrowheads
2, 3, 4 and 5 of lane peak $\mathrm{x}$ were $67 \mathrm{KDa}, 34 \mathrm{KDa}$, $27 \mathrm{KDa}$ and $15 \mathrm{KDa}$, respectively. These proteins correspond to albumin, apolipoprotein E, A-I and Cs (C-I, C-II, C-III), respectively ${ }^{[22,23]}$. The protein of arrowhead 2 of lane peak $x$ in Fig. 7B and 7C was detected by Western blotting with anti-apoloipoprotein $\mathrm{B}$ and the molecular weight was $260 \mathrm{kDa}$, indicating apolipoprotein B-48 $8^{[24]}$. Figure $7 \mathrm{~B}$ also shows the additional protein of arrowhead 3 in the lane peak $\mathrm{X}$, but it remains unspecified. The lipid composition of the peak $\mathrm{x}$ was as followed: free cholesterol $=6 \%$, cholesteryl esters $=15 \%$, triglyceride $=66 \%$ and phospholipids $=13 \%$.

\section{DISSCUSION}

The present study demonstrates that the peak $\mathrm{x}$ contains small size chylomicrons with a part of VLDL 


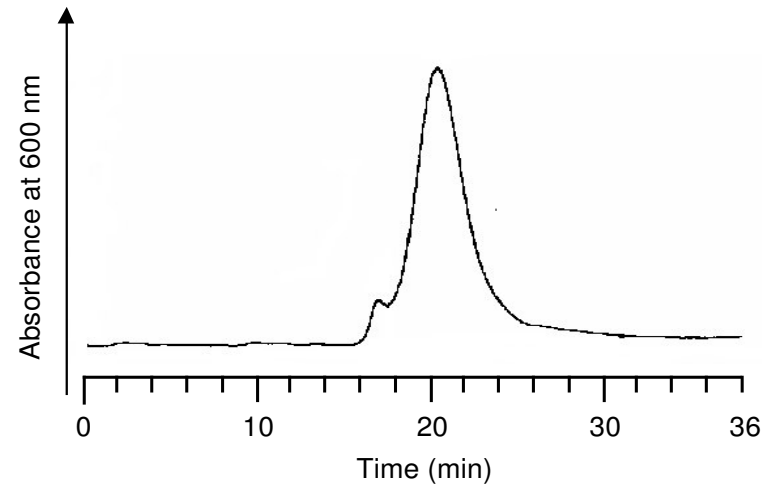

Fig. 4: Gel-permeation chromatogram of the fractionated peak $x$ collected by the cation-exchange HPLC. Seven $\mu \mathrm{L}$ of the peak $\mathrm{x}$ sample was analyzed by gel-permeation chromatography. The connected column of two TSK-gel LipopropakXL (7.8 mm I.D. $x$ $300 \mathrm{~mm}$ in size, Tosoh corp., Japan) was used. The cholesterol level of the eluate was monitored by using an enzymatic cholesterol reagent. Retention times of peak 1 and 2 were 16.85 and 20.93 min, respectively.

(Fig. 2). In the cation-exchange chromatography method, the large chylomicrons are hardly eluted from the column. Therefore, the pressure of the column becomes high when analyzing serum samples and the column should be exchanged to a new column whenever 100-200 samples have been analyzed ${ }^{[17]}$. When estimating the fractionated peak $\mathrm{x}$, the high molecular weight part of lipoproteins, larger than VLDL, was included and apolipoprotein B-100, B-48, E, A-I and Cs (C-I, C-II, C-III) were found in the peak $\mathrm{x}$ (Fig. 4 and 5). It is generally known that VLDL and chylomicrons have apolipoprotein B-100, B-48, A-I and Cs (C-I, C-II, C-III) and apolipoprotein B-100, E, A-I and Cs (C-I, C-II, C-III), respectively ${ }^{[23,24]}$. These results suggest the presence of small size chylomicrons and a part of VLDL in the peak x. Kane et al. reported LDL contained apolipoprotein B-100 (molecular weight, $549 \mathrm{KDa}$ ) and two large proteins designated B-74 (molecular weight, 407KDa) and B-26 (molecular weight, $144.5 \mathrm{KDa}$ ), complementary fragments of apolipoprotein B-100 ${ }^{[24]}$. Therefore, the 400KDa band in the peak $x$ (arrowhead 3 of lane peak $x$ in Fig. 6B) presumably might be the same product as B-74 reported by Kane et al. ${ }^{[24]}$.

Campos et al. reported that the composition of lipid and protein (cholesteryl esters, triglyceride, free cholesterol, phospholipids and proteins) of RLP was $8.4,60.7,5.5,16.9$ and $8.5 \%$, respectively ${ }^{[25]}$. In addition, the apolipoproteins of the RLP were apolipoprotein B-100, B-48, E and $\mathrm{Cs}^{[25]}$. This reported composition of RLP was very similar to the fractionated peak $x$ composition in the present study. The cholesterol levels of the peak $x$ were correlated significantly with RLP-C (Fig. 3D). As reported previously, high RLP-C

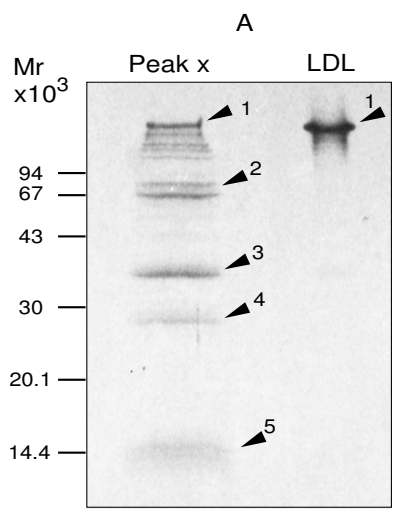

B
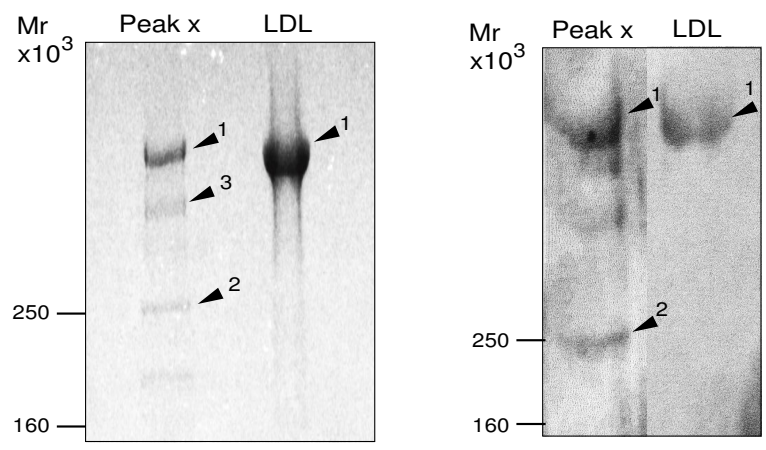

Fig. 5: SDS-PAGE and Western blotting experiments for the fractionated peak x. Samples of the fractionated peak $\mathrm{x}$ acquired by the HPLC method and LDL separated from healthy serum by the ultracentrifugation method were analyzed by SDS-PAGE and Western blotting experiments. A: A $15 \%$ polyacrylamide gel was used for SDS-PAGE. The molecular weight of the arrowheads 2, 3, 4 and 5 on lane peak $\mathrm{x}$ is $67 \mathrm{KDa}$, $34 \mathrm{KDa}, 27 \mathrm{KDa}$ and $15 \mathrm{KDa}$, respectively. Arrowhead 1 of lane peak $\mathrm{x}$ and lane LDL is apolipoprotein B-100. Arrowheads 2, 3, 4 and 5 of lane peak $x$ are albumin, apolipoproteins E, A-I and Cs (C-I, C-II, C-III), respectively. B: A 5\% polyacrylamide gel was used for SDS-PAGE. The molecular weight of arrowhead 1 of lane peak $\mathrm{x}$ and lane LDL is $540 \mathrm{KDa}$, indicating apolipoprotein B-100. Arrowhead 2 of lane peak $x$ is $260 \mathrm{KDa}$, indicating apolipoprotein B-48. Arrowhead 3 (molecular weight, 400KDa) of lane peak $\mathrm{x}$ is an unknown band. C: A $4-20 \%$ gradient polyacrylamide gel was used for Western blotting experiment with the anti-apolipoprotein B antibody. Molecular weight markers are shown at the left. The arrowhead 1 of lane peak $\mathrm{x}$ and lane LDL is apolipoprotein B-100 and arrowhead 2 of lane peak $\mathrm{x}$ is apolipoprotein B-48.

levels in sera predict future coronary events in patients with $\mathrm{CAD}^{[26]}$. We thought that the cholesterol levels of the peak $\mathrm{x}$ might be helpful for assessing a risk maker for atherosclerotic diseases, but it remained to be examined. 
In conclusion, the present study demonstrates that the lipoprotein peak $\mathrm{x}$ is one of TG rich lipoprotein fractions containing small size chylomicrons and a part of VLDL and that the peak $\mathrm{x}$ is presumably relevant to RLP.

Abbreviations used: HPLC, high-performance liquid chromatography (or chromatographic), HDL, high-density lipoprotein, LDL, low-density lipoprotein, IDL, intermediate-density lipoprotein, VLDL, very-low-density lipoprotein, TC, total cholesterol, TG, triglyceride, HDL-C, HDL cholesterol, LDL-C, LDL cholesterol, VLDL-C, VLDL cholesterol, SD, standard deviation, RLP, remnant-like particles, RLP-C, cholesterol level of remnant-like particles, SDS-PAGE, sodium dodecyl sulfate polyacrylamide gel electrophoresis, CHD, coronary heart disease.

\section{ACKNOWLEDGMENT}

We wish to thank Ms. M. Komori for her excellent technical assistance.

\section{REFERENCES}

1. Multiple Factor Intervention Trial Research Group, 1982. Multiple Risk Factor Intervention Trial. Risk factor changes and mortality results. J. Am. Med. Assoc., 248: 1465-1477.

2. Third Report of the National Cholesterol Education Program (NCEP), 2002. Expert Panel on detection, evaluation and treatment of high blood cholesterol in adults (Adult Treatment Panel III) Final Report. Circulation, 106: 3143-3421.

3. Mirai, A., T. Tanaka, T. Miyahara and M. Kameyama, 1981. Lipoprotein abnormalities in the pathogenesis of cerebral infarction and transient ischemic attack. Stroke, 12: 167-172.

4. Higgins, M., J.B. Keller, L.E. Wagenkneckt, M.C. Townsend, D. Sparrow, D.R. Jacobs and G. Hughes, 1991. Pulmonary function and cardiovascular risk factor relationships in black and in white young men and women. The CARDIA Study. Chest, 99: 265-266.

5. Saito, D., T. Shiraki, T. Oka, A. Kajiyama and T. Takamura, 2002. Risk factors indicating recurrent myocardial infarction after recovery from acute myocardial infarction. Circ. J., 66: 877-880.

6. Steinberg, D., 1983. Lipoproteins and atherosclerosis. A look back and a look ahead. Arteriosclerosis, 3: 283-301.

7. Havel, R.J., H.A. Eder and J.H. Bragdon, 1995. The distribution and chemical composition of ultracentrifugally separated lipoproteins in human serum. J. Clin. Invest., 34: 1345-1353.
8. Schumaker, V.N. and D.L. Puppione. 1986. Sequential flotation ultracentrifugation. Methods Enzymol., 128: 155-170.

9. Caslake, M.J. and C.J. Packard, 2000. The Use of Ultracentrifugation for the Separation of Lipoproteins. In Handbook of Lipoprotein Testing 2nd Edn. (Eds. N. Rifai, G.R. Warnick and M.H. Dominiczak), pp: 625-646. The American Association for Clinical Chemistry, Inc. Press, Washington, D.C.

10. Hoefner, D.M., S.D. Hodel, J.F. O'Brien, E.L. Branum, D. Sun, I. Meissner and J.P. McConnell, 2001. Development of a rapid, quantitative method for LDL subfractionation with use of the Quantimetrix Lipoprint LDL System. Clin. Chem., 47: 266-274.

11. Kido, T., H. Kurata, A. Matsumoto, R. Tobiyama, T. Musha, K. Hayashi, S. Tamai, K. Utsunomiya, N. Tajima, N. Fidge, H. Itakura and K. Kondo, 2001. Lipoprotein analysis using agarose gel electrophoresis and differential staining of lipids. J. Atheroscler. Thromb., 8: 7-13.

12. Okazaki, M., K. Sasamoto, T. Muramatsu and S. Hosaki, 2000. Analysis of plasma lipoproteins by gel permeation chromatography. In Handbook of Lipoprotein Testing 2nd Edn. (Eds. N. Rifai, G.R. Warnick and M. H. Dominiczak), pp: 647-669. The American Association for Clinical Chemistry, Inc. Press, Washington, D.C.

13. Scheffer, P.G., S.J.L. Bakker, R.J. Heine and T. Teerlink, 1998. Mesurement of LDL particle size in whole plasma and serum by high performance gel-filtration chromatography using a fluorescent lipid probe. Clin. Chem., 44: 2148-2151.

14. Usui, S., Y. Hara, S. Hosaki and M. Okazaki, 2002. A new on-line dual enzymatic method for simultaneous quantification of cholesterol and triglycerides in lipoproteins by HPLC. J. Lipid Res., 43: 805-814.

15. Haginaka, J., Y. Yamaguchi and M. Kunitomo, 1995. Anion-exchange high-performance liquid chromatographic assay of plasma lipoproteins. Anal. Biochem., 232: 163-171.

16. Hirowatari Y., H. Yoshida, H. Kurosawa, K. Doumitu and N. Tada, 2003. Mesurement of cholesterol of major serum lipoprotein classes by anion-exchange HPLC with perchlorate ion-containing eluent. J. Lipid Res., 44: 1404-1412.

17. Hirowatari Y., H. Kurosawa, H. Yoshida, K. Doumitu and N. Tada, 2002. Analysis method for lipoproteins by high-performance liquid chromatography with sulfopropyl-ligand column and magnesium ion-containing eluents. Anal. Biochem., 308: 336-342. 
18. Leary, E.T., T. Wang, D.J. Baker, D.D. Cilla, J. Zhong, G.R. Warnick, K. Nakajima and R.J. Havel, 1998. Evaluation of immunoseparation method for quantitative measurement of remnant-like particle-cholesterol in serum and plasma. Clin. Chem., 44: 2490-2498.

19. Hodis, H.N., 1999. Triglyceride-rich lipoprotein remnant particles and risk of atherosclerosis. Circulation, 99: 2852-2854.

20. Hirany, S., D.O'Byrne, S. Devaraj and I. Jialal, 2000. Remnant-like particle-cholesterol concentrations in patients with type 2 diabetes mellitus and end-stage renal disease. Clin. Chem., 46: 667-672.

21. Wilhelm, M.G. and A.D. Cooper, 2003. Induction of atherosclerosis by human chylomicron remnants: A hypothesis. J. Atheroscler. Thromb., 10: 132-139.

22. Weidman, S.W., J.B. Ragland and S.M. Sabesin, 1982. Plasma lipoprotein composition in alcoholic hepatitis: Accumulation of apoplipoprotein E-rich high density lipoprotein and preferential reappearance of "light"-HDL during partial recovery. J. Lipid Res., 23: 556-569.
23. Scheafer, E.J., S. Eisenberg and R.I. Levy, 1978. Lipoprotein apoprotein metabolism. J. Lipid Res., 19: 667-687.

24. Kane, J.P., D.A. Hardman and H.E. Paulus, 1980. Heterogeneity of apoolipoprotein B: Isolation of a new species from human chylomicrons. Proc. Natl. Acad. Sci. U.S.A., 77: 2465-2469.

25. Campos, E., L. Kotite, P. Blanche, Y. Mitsugi, P.H. Frost, U. Masharani, R.M. Kruss and R.J. Havel, 2002. Properties of triglyceride-rich and cholesterol-rich lipoproteins in the remnant-like particle fraction of human blood plasma. J. Lipid Res., 43: 365-374.

26. Kugiyama K., H. doi, K. Takazoe, H. Kawano, H. Soejima, Y. Mizuno, R. Tsunoda, T. Sakamoto, T. Nakano, K. Nakajima, H. Ogawa, S. Sugiyama, M. Yoshimura and H. Yasue, 1999. Remnant lipoprotein levels in fasting serum predict coronary events in patients with coronary artery disease. Circulation, 99: 2858-2860. 